\title{
Conhecimento profissional de professores que lecionam para os anos iniciais: conhecimentos sobre o tema área de figuras planas
}

\author{
Angélica da Fontoura Garcia Silva \\ Susana Maris França da Silva \\ Maria Elisa Esteves Lopes Galvão
}

\section{Resumo}

Expomos neste artigo resultados de um estudo que buscou identificar conhecimentos sobre área de figuras planas explicitados por um grupo de professoras no início e durante os estudos realizados na própria escola em que trabalhavam. As quatro participantes desta investigação lecionam matemática para os anos iniciais do Ensino Fundamental em uma escola particular de uma cidade da grande São Paulo. Os dados foram coletados por meio da aplicação de um questionário de caráter diagnóstico, no início do processo formativo, e por meio da observação realizada durante uma sessão de estudos do grupo. As respostas das professoras ao questionário inicial indicaram haver limitações no conhecimento a respeito do cálculo de área de figuras planas e no uso de material manipulativo. Além disso, evidenciaram que os estudos e as vivencias sobre a utilização do Tangram como recurso metodológico para o ensino de área de figuras planas favoreceram a reflexão coletiva sobre as possibilidades não só para o cálculo de área mas também a respeito da reconfiguração de figuras, da conservação de áreas e da compreensão das fórmulas utilizadas para o seu cálculo.

Palavras-chave: Educação Matemática. Grupos de Estudo. Conhecimento Profissional. Ensino de área. 


\title{
PROFESSIONAL KNOWLEDGE OF TEACHERS WHO TEACH FOR THE INITIAL YEARS: KNOWLEDGE ON THE SUBJECT AREA OF FLAT FIGURES
}

\author{
Angélica da Fontoura Garcia Silva \\ Susana Maris França da Silva \\ Maria Elisa Esteves Lopes Galvão
}

\begin{abstract}
We presente in this article results of a study that sought to identify knowledge about the área of flat figures made explicit by a group of teachers at the beginning and during the studies carried out at school where they worked. The four participants in this research teach matematics for the early years of elementar school in a private scholl in a city in greater São Paulo. Data were collected thourgh the application of a diagnostic questionnaire at the beginning of the training process and through observation during a group study session. The teachers answers to the initial questionnaire indicated that there are limitations in their knowledge about the calculation of flat figure area and the use of manipulative material. In addition, they showed that studies and experiences on the use of Tangram as a methodological resource for teaching flat figure areas favored a collective reflection on the possibilities not only for area calculation but also on the reconfiguration of figures, conservation of areas and understanding of the formulas used for their calculation.
\end{abstract}

Keywords: Mathematics Education. Study Groups. Professional knowledge. Area teaching. 


\section{Introdução}

Esta investigação foi desenvolvida com a participação de um grupo que se reúne na escola para estudar pressupostos que envolvem o conceito de área e perímetro de figuras planas. Para mostrar a relevância de estudarmos o desenvolvimento de conhecimentos profissionais de professores participantes de um grupo de estudos nos inspiramos em pesquisas como as de Miranda (2014) e Correia (2018), cujos resultados mostram que professores que se organizam para estudar juntos na própria escola em que lecionam ampliaram seus conhecimentos a respeito das temáticas estudadas e seu ensino. Miranda (2014) também deixa claro que, ao refletir sobre suas ações, as professoras participantes do grupo deixaram de ter um papel exclusivo de aprendiz e de utilizar apenas de momentos destinados à formação para discutir a temática e passaram a se sentir sujeito importante da construção de mudanças da prática.

Para justificar o tema área de figuras planas apoiamo-nos em estudos internacionais e nacionais os quais mostram a complexidade da temática e as dificuldades de alunos e professores quando o estudam e o ensinam. Acerca do ensino do conceito de área tomamos como referências os estudos de Clements e Stephan (2004). Os autores consideram que a compreensão do conceito de área é complexa, uma vez que envolve diversas ideias matemáticas, como o entendimento do significado da unidade bidimensional de medida, do cálculo da área por meio da reunião de figuras, da equivalência de áreas, da composição e decomposição de figuras. Os autores afirmam que a compreensão dessa temática depende de saber que ao decompor ou reorganizar formas adequadamente a sua área se mantém. Afirmam ainda que tal complexidade é uma possível geradora das dificuldades encontradas por alunos e professores que estudam e ensinam área de figuras planas.

Quanto à aprendizagem dos estudantes da Educação Básica, Kamii e Kysh (2006) observam que o quadrado unitário não é considerado em geral, pelos estudantes, como a unidade de medida de área e também não é utilizado para construir decomposições de figuras geométricas simples. Já Facco (2003) identificou as dificuldades de um grupo de alunos ao trabalhar com a reconfiguração, ou seja, a composição/decomposição para o cálculo de áreas. Da mesma forma que as investigações anteriores Baturo e Nason (1996), Pessoa (2010), Garcia Silva, Galvão e Campos (2013) analisaram conhecimentos de futuros professores e professores que lecionam matemática para os anos iniciais área de figuras planas e identificaram ser recorrente um repertório limitado de conhecimentos sobre o conteúdo e sobre o ensino dessa temática. Evidenciaram também que as abordagens dinâmica e estática sobre área e perímetro não estão incluídas nos currículos, limitando assim sua compreensão; e revelaram que o processo de cálculo da área é, em geral, apenas baseado na contagem de quadradinhos de uma malha quadriculada associada à figura ou na memorização e aplicação de fórmulas. Uma

ISSN 2526-2882

$$
67 *
$$


tendência revelada pelas pesquisas é associar a área como apenas a multiplicação do comprimento pela largura, desvinculada das experiências concretas de medição, o que resulta na não correlação entre a medida obtida e o que se está medindo, e as unidades de medida uni e bidimensionais.

A partir dessas constatações, este artigo apresenta uma análise dos conhecimentos evidenciados por um grupo de professoras que estudavam a utilização do Tangram como recurso de ensino de área de figuras planas para os anos iniciais. Os dados aqui coletados foram analisados na perspectiva de Ball, Thames e Phelps (2008) e nos estudos que tratam das questões relativas aos processos de ensino e aprendizagem do cálculo de área de figuras planas. Para analisar as informações sobre o grupo de estudos nos referenciamos nas investigações de Nacarato (2000) e Fiorentini (2004) os quais também serão expostos a seguir.

\section{Considerações Teóricas}

Para elaborar o questionário e analisar os resultados encontrados tanto durante a realização do questionário como nos estudos do grupo de professoras, levamos em conta os pressupostos sobre o conhecimento profissional docente apresentados no estudo de Ball, Thames e Phelps (2008). Para este artigo analisaremos uma das categorias de conhecimentos para o ensino estabelecidas por pelos autores. Ball, Thames e Phelps (2008) fundamentados nos estudos de Shulman (1986) ampliaram a categorização para o ensino da matemática e consideraram o conhecimento do conteúdo (comum/horizontal/especializado) e o conhecimento pedagógico do conteúdo (do conteúdo e dos estudantes/ do conteúdo e do ensino/ conhecimento curricular).

No tocante à constituição de grupos de estudos, além das investigações citadas na introdução deste artigo nos inspiramos em pesquisas como as de Nacarato (2000) e Fiorentini (2004). Os resultados dessas investigações nos ajudaram a justificar a importância de investigarmos grupos de professores que estudam juntos. Nacarato (2000) mostra a relevância de se constituir um grupo de estudo na própria escola em que o professor leciona, segundo essa autora: "o fato de existir o grupo dentro da própria escola, e com reuniões freqüentes, dá às professoras soluções rápidas aos dilemas que surgem, possibilitando que não haja interrupções no desenvolvimento das atividades com as crianças" (NACARATO, 2000, p. 284-285). Assim, tal estudo mostrou a relevância da nossa opção pela constituição de um grupo que se reúne para estudar matemática na própria escola.

Fiorentini (2004) nos ajudou a identificar características de colaboração no grupo investigado. $\mathrm{O}$ autor discute características ligadas à constituição de um grupo de estudo com caráter colaborativo e destaca o desejo dos participantes de trabalhar e estudar coletivamente, resultante de um sentimento de inacabamento e incompletude como profissionais, uma vez 
que, segundo o autor, se tem "a percepção de que sozinho é difícil dar conta desse empreendimento". (FIORENTINI, 2004, p. 54). O autor apresenta algumas características que identificam um grupo colaborativo e, dentre elas, destacamos:

- a participação é voluntária e todos os envolvidos desejam crescer profissionalmente e buscam autonomia profissional;

- $\quad$ há um forte desejo de compartilhar saberes e experiências, reservando, para isso, um tempo livre para participar do grupo;

- $\quad$ os participantes sentem-se à vontade para expressar livremente o que pensam e sentem e estão dispostos a ouvir críticas e a mudar;

- $\quad$ não existe uma verdade ou orientação única para as atividades. Cada participante pode ter diferentes interesses e pontos de vista, aportando distintas contribuições e diferentes níveis de participação;

- $\quad$ as tarefas e atividades dos encontros são planejadas e organizadas de modo a garantir que o tempo da reunião do grupo seja o mais produtivo possível;

- a confiança e o respeito mútuo são essenciais ao bom relacionamento do grupo

- $\quad$ os participantes compartilham significados acerca do que estão fazendo e aprendendo e o que isso significa para suas vidas prática e profissional;

- $\quad$ há reciprocidade de aprendizagem. [...] Os acadêmicos aprendem com os professores escolares os saberes experenciais que estes produzem no contexto complexo e adverso da prática escolar re-significando assim seus saberes profissionais enquanto formadores de professores. Os professores, face aos seus desafios e problemas, com a ajuda dos acadêmicos, produzem [...] re-significações sobre o que sabem e fazem. (FIORENTINI, 2004, p. 5960)

Reiteramos que neste estudo procuraremos identificar também se tais características foram observadas durantes as sessões investigadas.

\section{Procedimentos Metodológicos}

Esta investigação, de natureza qualitativa, foi desenvolvida por meio da aplicação de um questionário a 25 licenciandos em Pedagogia de uma universidade particular na região norte do estado do Paraná. As perguntas visaram analisar a formação e a compreensão dos participantes inerentes a aspectos ligados ao conceito de área. É importante destacar que, de acordo com os participantes deste estudo, anteriormente a realização desta pesquisa eles não haviam estudado ou discutido questões que envolvessem esses assuntos, informação essa confirmada com o professor da turma.

Apresentamos um recorte de uma pesquisa de natureza qualitativa, realizada em uma escola particular localizada em uma cidade da grande São Paulo - Brasil, que contou com a participação de quatro professoras que lecionam matemática para os anos iniciais. As professoras participantes são docentes da instituição e foram identificadas, na pesquisa, por nomes de flores para preservar suas identidades: Professoras Acácia, Violeta, Jasmim e Watsonia. Duas dentre as participantes atuam nos anos iniciais há menos de dois anos; as ISSN 2526-2882

$$
69 *
$$


outras duas atuam há 14 e 32 anos, respectivamente. Em diferentes momentos, todas concluíram o ensino superior em Pedagogia.

Uma vez organizado o grupo, as atividades tiveram início com a aplicação de um questionário diagnóstico com o objetivo de fazer um levantamento sobre as concepções e conhecimentos das participantes a respeito do conceito de área e seu ensino. A análise dos dados desse diagnóstico orientou as atividades posteriormente realizadas, que buscaram discutir e ampliar os conhecimentos para o ensino a respeito de área de figuras planas mediante estudos realizados em grupo na própria escola.

As informações aqui consideradas para análise foram coletadas durante as sessões de estudo por meio de registros escritos da resolução das atividades pelos professores e videogravações das sessões de estudo do grupo para posterior transcrição.

Para este artigo analisamos as sessões de estudo das quais todas as professoras participaram, nas quais foram discutidas as atividades relativas à área com o uso do Tangram: a atividade proposta no questionário diagnóstico inicial, e, posteriormente, as atividades discutidas no âmbito do grupo de estudo a respeito de composição e decomposição de figuras com a utilização das peças do Tangram. Essas atividades foram propostas a partir da análise das resoluções apresentadas pelas professoras no diagnóstico.

A seguir descrevemos a análise dos dados coletados por meio do questionário inicial e em uma das sessões que estudou possibilidades de utilização do Tangram para o ensino de área de figuras planas.

\section{Discussão e análise dos dados do diagnóstico inicial}

Ao apresentarmos às participantes do grupo um questionário inicial - de caráter diagnóstico - procuramos investigar os conhecimentos explicitados antes da realização dos estudos em grupo. A atividade que envolvia o Tangram foi escolhida por acreditarmos que esse material poderia ser conhecido pelas professoras, uma vez que o trabalho realizado a partir da exploração de objetos pertencentes ao mundo físico, como o quebra-cabeça, também é indicado em documentos curriculares vigentes na época, Parâmetros Curriculares Nacionais PCN: [...] se esse trabalho for feito a partir da exploração dos objetos do mundo físico, de obras de arte, pinturas, desenhos, esculturas e artesanato, ele permitirá ao aluno estabelecer conexões entre a Matemática e outras áreas do conhecimento (BRASIL, 1997, p. 39).

Com essa questão, reproduzida na Figura 1, tínhamos a intenção também de identificar a forma como o grupo analisava a área de uma parte da figura em relação à figura como um todo. O Tangram é um quebra-cabeça chinês que pode ser utilizado nas aulas de matemática. Ele é composto de sete peças que formam um quadrado como o da figura a seguir. Imagine que as sete peças juntas tenham $48 \mathrm{~cm}^{2}$. Determine a área do paralelogramo cinza. 
Figura 1 - Questão do instrumento de pesquisa sobre a área das peças do Tangram.

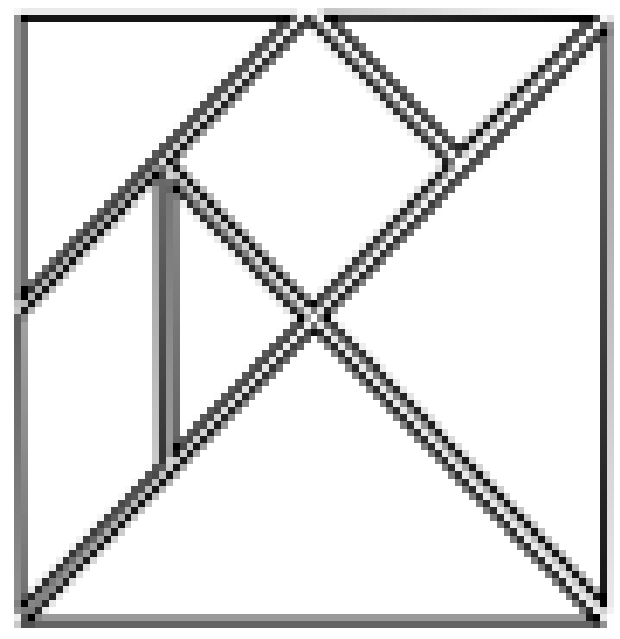

Fonte: Acervo da Pesquisa

Figura 2 - Protocolo apresentado pela Professora Jasmim

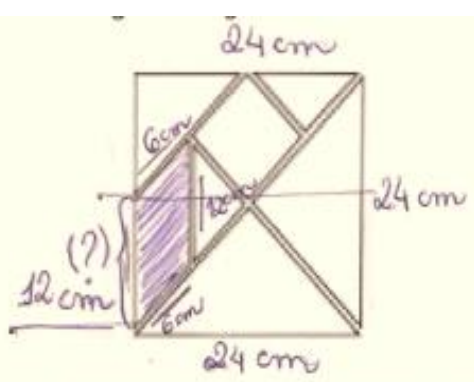
Imagine que as sete peças juntas tenham $48 \mathrm{~cm}^{2}$ Determine a área do
paralelogramo cinza.

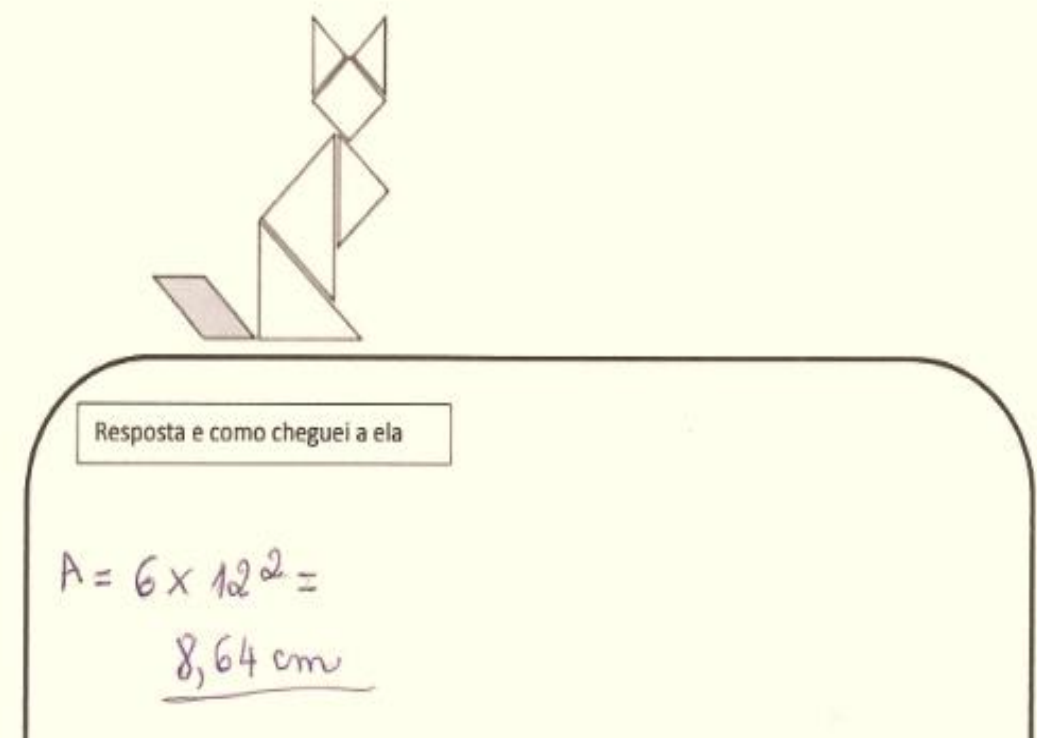

Fonte: Acervo da pesquisa

ISSN 2526-2882

$71 \%$ 
Analisando as estratégias utilizadas pelas participantes observamos que Jasmim tentou associar medidas a algumas das figuras que compõem o Tangram e efetuar cálculos sem apresentar justificativas, conforme é possível verificar na Figura 2.

É possível notar também que ao procurar deduzir a medida dos lados do paralelogramo, Jasmim estimou a relação entre as medidas dos lados das figuras, mas equivocou-se ao calcular a medida do lado do quadrado formado pelas sete peças do Tangram (também hipotenusa do triângulo maior). A professora, inicialmente, procurou encontrar o valor do lado do quadrado, considerando que ele media a metade da área e não sua raiz quadrada, deduzindo que essa medida seria $24 \mathrm{~cm}$. Em seguida, com base na percepção visual da composição do quadrado, concluiu que a medida do lado maior do paralelogramo seria a metade da medida da hipotenusa referente ao triângulo maior e deduziu que essa medida seria $12 \mathrm{~cm}$. Deduziu também que o lado menor do mesmo paralelogramo seria a metade do lado maior $-6 \mathrm{~cm}$. Além disso, foi possível identificar que essa participante considerou que para medir a área do paralelogramo precisaria calcular o produto entre a medida do lado menor pelo quadrado da medida do lado maior. Analisando o ocorrido obtivemos evidências de que essa participante conseguiu identificar as relações estabelecidas entre os lados dos sete polígonos que compunham o quadrado maior. Todavia constatamos confusões com a identificação das medidas e também com as fórmulas para o cálculo da área do quadrado e do paralelogramo.

Figura 3- Protocolo apresentado pela professora Watsonia
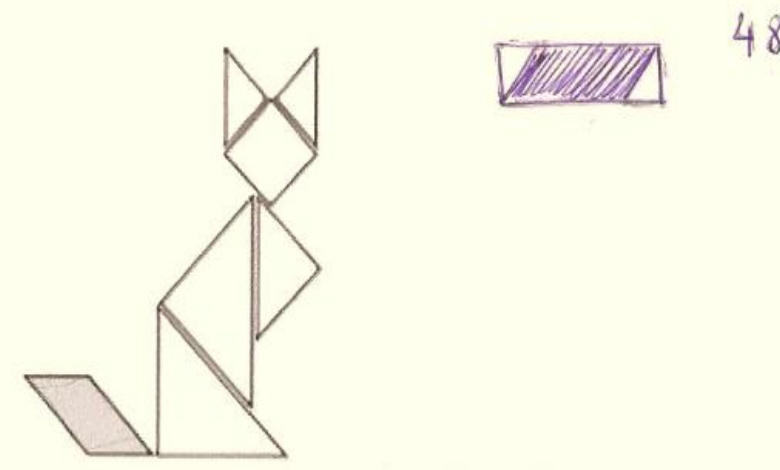

Fonte: Acervo da pesquisa

Watsonia não soube como chegar ao resultado da área para essa figura, o que a fez não responder à questão, como nos mostra o protocolo na Figura 3. Foi possível observar, entretanto, que a participante tentou relacionar o paralelogramo com o retângulo, mas isso não permitiu que ela encontrasse uma estratégia que lhe permitisse resolver a situação.

ISSN 2526-2882

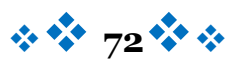


A Professora Violeta, ao analisar a figura que representa o Tangram, disse: "eu não sei, porque é a primeira vez que tento calcular a área desse tipo de figura" (PROFESSORA VIOLETA).

Analisando o ocorrido no âmbito do diagnóstico, foi possível identificar que, antes de realizarem os estudos em grupo, nenhuma das professoras participantes conseguiu relacionar a medida da área da figura cinza com a área total da figura ou mesmo estabelecer corretamente uma relação entre as figuras que compõem o Tangram. Essa análise, juntamente com as das demais situações apresentadas no questionário, nos levou a preparar as sessões de estudo com o propósito de aprofundar a percepção/compreensão das professoras participantes sobre medidas de área. Assim, durante as sessões de estudos, dentre outras atividades, procuramos, por meio da utilização do Tangram como material de apoio, discutir questões concernentes à comparação de figuras poligonais de formatos diferentes, e das medidas de suas áreas. Nossa escolha se deu baseada na expectativa de que tal experiência pudesse levar o professor a discutir e refletir sobre a composição e a decomposição dos polígonos, o cálculo da área dos polígonos presentes no quebra-cabeças e também sobre a relação entre o valor da área e a unidade de medida de referência.

\section{Discussão e análise dos dados coletados durante os estudos em grupo}

Como pudemos observar, todas as professoras investigadas neste estudo, naquele momento inicial, tiveram dificuldade para responder à questão descrita anteriormente. Descobrimos ainda que nenhuma delas se utilizava, antes dos nossos estudos, de materiais manipuláveis para desenvolver o ensino de áreas e perímetros: "Eu nem conhecia o material, aliás, nunca dei aula de área utilizando nada de material [referindo-se a material manipulável]” (PROFESSORA JASMIM). Analisando o ocorrido, verificamos que a limitação de conhecimentos comuns do conteúdo pode ter limitado, da mesma forma, o conhecimento do Conteúdo e do Ensino e Curricular acerca desse tema, assim descrito por Ball, Thames e Phelps (2008).

Ao evidenciarmos a dificuldade apresentada pelas professoras investigadas, preparamos algumas atividades para que pudéssemos aprofundar a percepção/compreensão desse grupo sobre medidas e outros conhecimentos relacionados à área. Isso se deu também porque encontramos, nas orientações oficiais, argumentos para justificar a necessidade de o professor vivenciar esse tipo de atividade. Os autores do PCN orientam os professores, por exemplo, para que eles desenvolvam em suas salas propostas como essa: 
conhecimento e possibilitem a comparação de grandezas de mesma natureza (PCN, 1997, p. 59).

Para construir o processo reflexivo, em que o grupo pudesse traçar estratégias para a obtenção dos resultados das áreas de figuras, utilizamos então as partes do Tangram de acordo com estratégias previamente estabelecidas. Primeiramente, exploramos a composição do Tangram propondo que as participantes utilizassem as suas peças para construírem quadrados utilizando exatamente: 2 peças, 3 peças, 4 peças, 5 peças e 7 peças.

Figura 4 - Protocolo da Professora Jasmim, analisando as estratégias que poderia usar para representar a figura solicitada

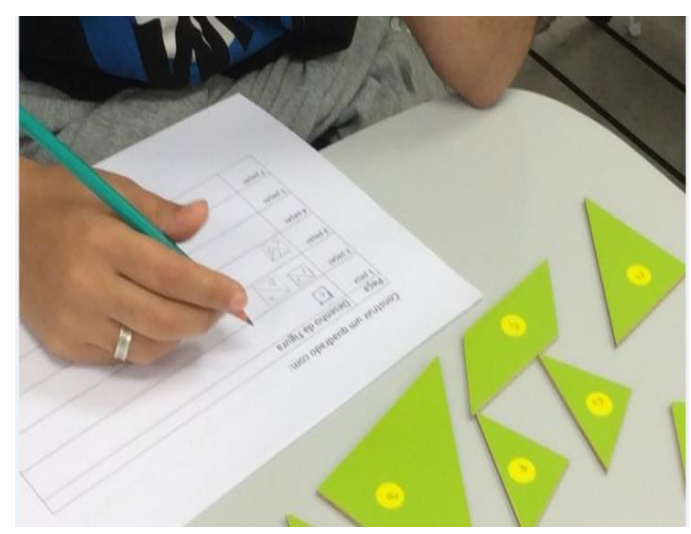

Fonte: Acervo da pesquisa

Nosso propósito era que as participantes explorassem o material e estabelecessem relações de composição utilizando as peças.

Figura 5 - Protocolo da Professora Jasmim, possibilidades encontradas sobre as formas solicitadas

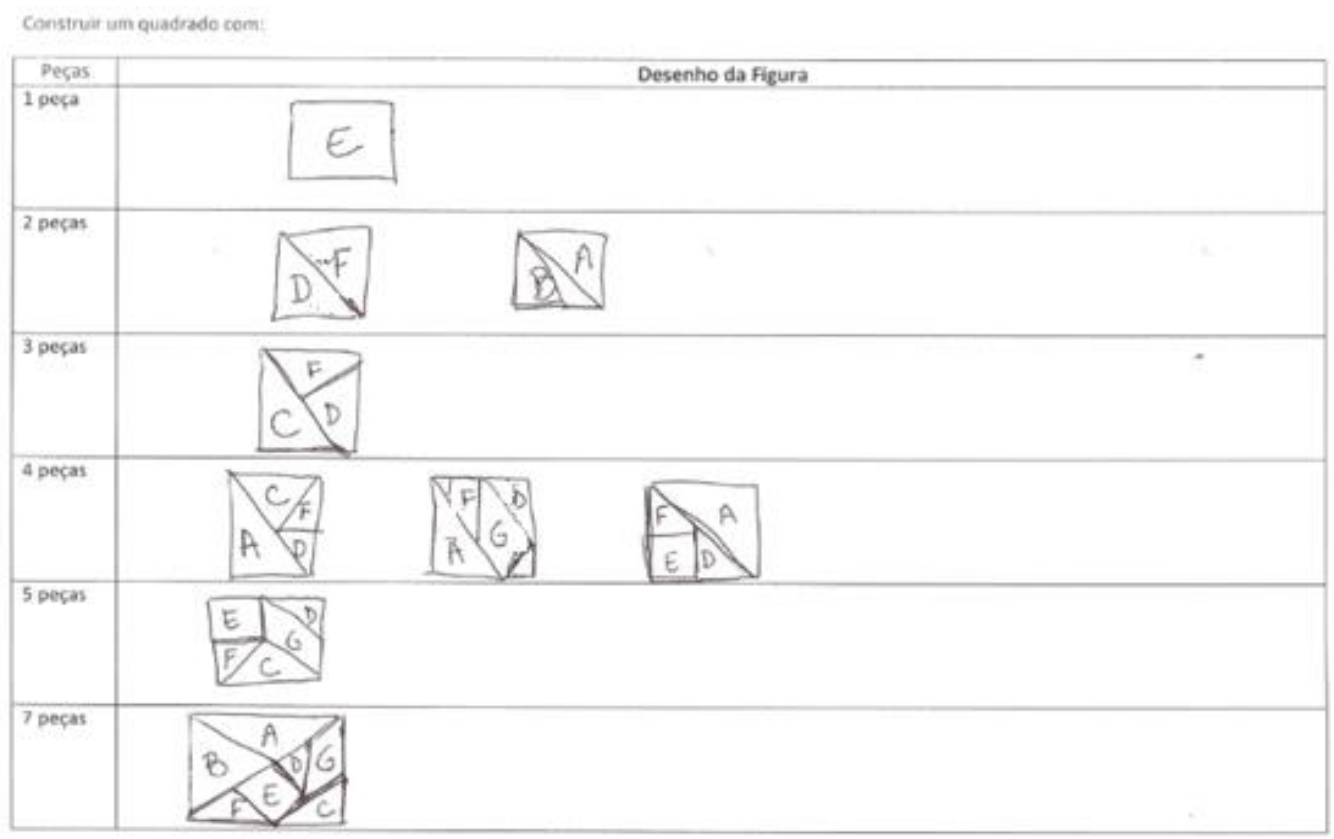

Fonte: Acervo da pesquisa

ISSN 2526-2882 
Jasmim, assim como as demais, compôs todas as figuras, mas durante o desenvolvimento da atividade notamos que ela resolveu rapidamente os três primeiros itens, mas demorou um pouco quando solicitamos que o quadrado possuísse 4, 5 e 7 peças. Watsonia foi a participante que encontrou mais dificuldade para compor os quadrados, mas no decorrer do processo percebeu que peças agrupadas poderiam sim formar um quadrado: "Fiquei um pouco desconfiada em perceber esses quadrados, mas realmente essas peças juntas estão formando um quadrado sim" (PROFESSORA WATSONIA).

Quando as professoras concluíram as construções dos quadrados possíveis com as peças do Tangram, perceberam que havia áreas que, embora com o formato diferente, possuíam a mesma medida. "Bem, as figuras A e B têm a mesma área, na figura G cabem duas figuras F, e na E também, então G e E têm a mesma área” (PROFESSORA ACÁCIA). Essa afirmação pode ser considerada como trivial, entretanto vale ressaltar que estudos como os de Kamii e Kysh (2006), ao analisarem o desempenho de alunos do $8 .^{\circ}$ e $9 .^{\circ}$ anos, observam que nem todos os estudantes reconhecem áreas iguais envolvendo formatos diferentes. Nessa investigação, as autoras solicitaram que os estudantes indicassem a área de duas pavimentações, nas quais as lajotas eram dispostas de duas formas diferentes como na Figura 6.

Figura 6 - Figura da Pesquisa de KAMII; KYCH
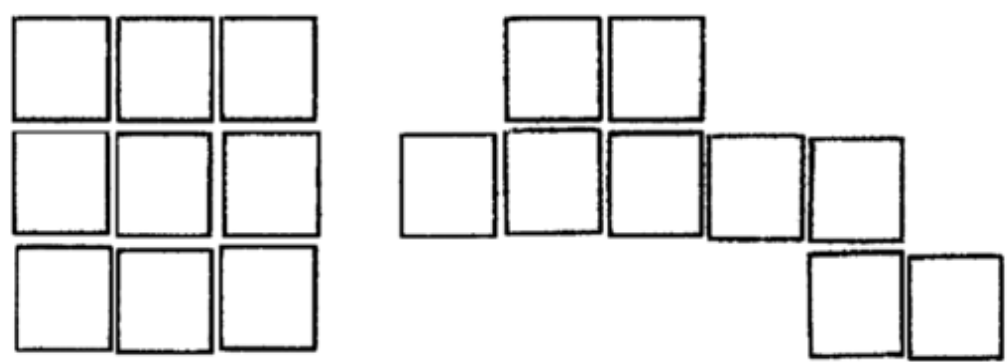

Fonte: KAMII; KYCH, 2006, p. 112

Analisando o ocorrido, as pesquisadoras verificaram que: “[...] para um terço (33\%) dos alunos da oitava série regular, no entanto, a 'área' pareceu mudar quando as mesmas nove cores de ladrilhos foram organizadas de forma diferente" (KAMII; KYCH, 2006, p. 112, tradução nossa).19 Relatando, ainda, a desconfiança de alguns da possibilidade de a forma irregular ter uma área, as autoras descrevem os seguintes comentários dos alunos: "Uma forma como essa tem uma área?” (Ibidem, tradução nossa)20 Nesse sentido, consideramos que essa

${ }^{19}$ For a third (33\%) of the Regular eighth graders, however, the "area" seemed to change when the same nine Color Tiles were arranged differently.

20 "Do shapes like this have an area?"

ISSN 2526-2882 
vivência pode ter permitido às professoras um novo olhar para o ensino do tema, e elas foram além da percepção de que figuras de formatos diferentes podem ter a mesma área.

A Professora Jasmim, por exemplo, acrescentou: "Gente que fantástico, podemos agora relacionar essas medidas baseadas no todo que a figura tem como queríamos". A partir dessa discussão, foi possível também ampliar a reflexão do grupo acerca da possibilidade de uma mesma peça representar frações diferentes dependendo do todo referência. Foi possível identificar que essa proposta permitiu ampliar a discussão a respeito do fato de que figuras diferentes possuem a mesma área. Além disso, o grupo também discutiu questões relacionadas ao significado parte todo para uma fração e à relação desse significado com a ideia de medir como comparação de grandezas de mesma espécie. Ao desenvolvermos esta atividade foi possível observar o que Fiorentini (2004) descreveu como compartilhamento de significados não só a respeito do que se estava fazendo ou aprendendo, mas sobre como isso pode ajudar os professores em sua vida profissional.

Aproveitando essa reflexão das participantes, propusemos então que cada uma identificasse a relação entre a área de cada figura e de cada figura toda, e para isso utilizamos as identificações presentes na atividade descrita anteriormente A, B, C, D, E, F e G. Fizemos as seguintes perguntas: Qual a relação da área da figura A com a área da figura toda? E para cada figura identificada com uma letra fizemos a mesma pergunta.

As respostas para esses questionamentos foram assim apresentadas pelas participantes:

Figura 7- Protocolo da Professora Jasmim, ao analisar as partes do Tangram, a participante representa as formas por meio de frações e porcentagem

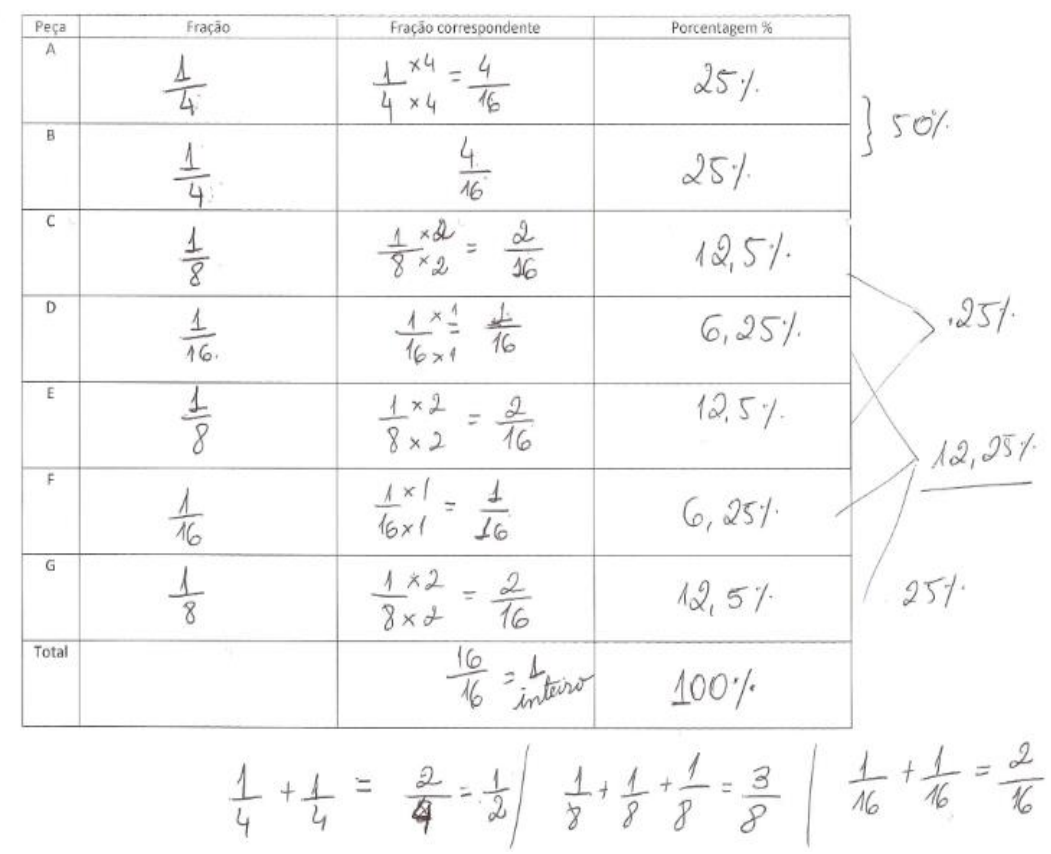

Fonte: Acervo da pesquisa ISSN 2526-2882 
Jasmim logo percebeu a fração que cada parte representava em relação ao todo. Além de expressar as frações, Jasmim transformou cada uma em frações equivalentes, determinou sua porcentagem e, ao somar as frações, identificou que todas juntas formavam 1 inteiro. "Faz muito sentido agora, todas as frações das peças juntas formam um 1 inteiro" (PROFESSORA JASMIM).

Acácia utilizou frações com um mesmo denominador para representar cada peça do Tangram, porém, ao adicionar as frações, cometeu um equívoco: adicionou tanto o numerador como o denominador. Em suas concepções, "ao somar as frações pensei que somávamos os dois números" (PROFESSORA ACÁCIA). A participante desmembrava o número fracionário acreditando serem números distintos. Aproveitamos para discutir sobre essa dificuldade e observamos que, infelizmente, parece ser recorrente apoiados em GARCIA SILVA, A. F. (2007). Fizemos a leitura de um trecho da tese da autora a qual observou que professores que lecionavam Matemática para os anos iniciais em uma escola pública de São Paulo também cometiam esse equívoco. Depois da leitura Acácia afirma:

\begin{abstract}
Eu concordo com ela; pra mim, a fração era como se fosse dois números naturais um em cima do outro, separados apenas por um traço, e eu fiz o que ela falou fiz a conta em cima e em baixo [referindo-se ao fato de ela operar com o numerador e o denominador, separadamente], e fiz o que ela disse mesmo [referindo-se ao texto de GARCIA SILVA, A. F.( 2007] fiz o registro utilizando um traço para separar os dois números e não olhei para a relação dos números. (PROFESSORA ACÁCIA)
\end{abstract}

Além disso, procuramos analisar outras dificuldades encontradas na atividade. A Professora Jasmim procura esclarecer:

\begin{abstract}
$\mathrm{Na}$ verdade quando o aluno fizer essa atividade precisa pensar como se a figura tivesse sido dividida em 16 partes, todas iguais, dessas dezesseis, por exemplo, a figura $\mathrm{E}$ possui 2, a $\mathrm{G}$ também possui 2, pois tem a mesma área, a A e a B possuem cada uma 4 das dezesseis partes, então para somarmos elas apenas somamos a parte de cima, pois representam as partes das 16 (PROFESSORA JASMIM).
\end{abstract}

Analisando a intervenção da professora, constatamos que ela parte de frações de dezesseis avos e utiliza a ideia de medida para adicionar as frações, tomando como unidade de medida o triângulo menor. Vale salientar que, mesmo considerando que o tema frações não era nosso objeto de investigação, esse episódio exemplifica muito bem a abrangência das discussões e reflexões acerca da Matemática ocorrida ao longo desse encontro. Notamos nesse episódio que a ampliação dos conhecimentos das professoras a respeito da área utilizando o Tangram como recurso lhes permitiu, também, uma melhoria na qualidade da reflexão tanto sobre o ensino desse tema como também sobre o ensino das frações.

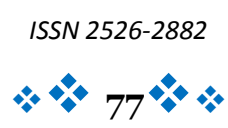


A Professora Watsonia, então, explicita compreender a relação entre as peças e suas diferentes representações. Ao final das discussões declara:

Esses encontros realmente estão me fazendo construir novos conhecimentos em relação àquilo que já usava, pois confesso que não compreendia o real sentido de estar fazendo esse processo até esse momento. Agora entendo aquela coisa de dividir pelo de baixo e multiplicar pelo de cima [referindo-se aos procedimentos utilizados para calcular a adição de frações] (PROFESSORA WATSONIA).

Foi possível constatar que as professoras envolvidas se valeram da equivalência de frações para ampliar sua compreensão a respeito da adição e seu ensino. Além disso, notamos que tal proposta favoreceu a compreensão sobre as diferentes representações dos números racionais.

Depois de fortalecidas as concepções das participantes concernente à relação parte/todo, retomamos as discussões sobre as fórmulas de área e ao longo delas pudemos deduzir as fórmulas de área para algumas das figuras planas. Ao final a professora Jasmim, comenta sobre sua resolução

Figura 8 - Protocolo da Professora Jasmim, com os comentários sobre sua solução na atividade diagnóstica

\begin{tabular}{|l|l|}
\hline $\begin{array}{l}\text { Lembra quando eu resolvi aquela questão do } \\
\text { Tangram lá no primeiro dia? Lá, eu até pensei que a } \\
\text { área do quadrado era lado vezes lado, mas depois na } \\
\text { hora de calcular achei a metade e não era metade, se } \\
\text { é lado vezes lado, mas o pior de tudo é que eu não } \\
\text { sabia que a área do paralelogramo era a mesma do } \\
\text { retângulo [referindo-se a fórmula para o cálculo da } \\
\text { área do retângulo]. Essa nossa vivência me ajudou } \\
\text { tanto a entender o porquê das fórmulas, antes eu } \\
\text { fazia sem saber o que estava fazendo. Agora acho que } \\
\text { consigo mostrar ao meu aluno porque a fórmula é } \\
\text { essa e não vou mais repetir como papagaio } \\
\text { (PROFESSORA JASMIM) }\end{array}$ \\
\hline $\begin{array}{l}A=6 \times 122^{2}= \\
8,64 \mathrm{~cm}\end{array}$
\end{tabular}

Fonte: Acervo da pesquisa

A análise feita pela professora Jasmim reproduzida na Figura 8 nos evidencia que ela ampliou seus conhecimentos a respeito do cálculo de área e seu ensino (BALL, THAMES E PHELPS, 2008). Notamos, ao longo das discussões, que as demais professoras também estavam mais seguras para resolver a questão inicial. Jasmim retomou a questão e afirmou: "Agora ficou fácil resolver a questão, o paralelogramo representa 1/8 da figura"; Watsonia então a interrompeu dizendo: "Isso mesmo, ou 12,5\% da figura, então a área cinza é de $6 \mathrm{~cm} 2$, ISSN 2526-2882 
porque 48 dividido por 8 é igual a 6" (PROFESSORA WATSONIA). Nesse momento todas as professoras concordam com ela. Nesse contexto acreditamos ter encontrado indícios de que houve ampliação dos conhecimentos das professoras participantes do grupo e acreditamos que essa ampliação pode estar diretamente relacionada aos estudos realizados pelo grupo de professores.

Analisando os resultados encontrados quando as participantes responderam ao questionário inicial é possível notar que seus conhecimentos sobre área do paralelogramo eram limitados. Todavia, durante a formação foi possível verificar que houve um avanço significativo da base de conhecimentos necessárias ao ensino como definida por Ball, Thames e Phelps (2008). Acreditamos que tal resultado foi fruto do processo formativo envolvendo esse grupo colaborativo de professores. Nesse contexto, acreditamos assim como Miranda (2014) e Correia (2018) que a constituição de grupos que desejem estudar na própria escola em que lecionam pode favorecer a (re)significação dos conhecimentos profissionais.

\section{Considerações Finais}

Diante das análises aqui expostas, podemos inferir que as sessões de formação permitiram que as professoras ampliassem seus conhecimentos não só no tocante à determinação de áreas de polígonos, mas também sobre seu ensino. Notamos ainda que houve ampliação da compreensão que as participantes tinham sobre as frações, suas representações e ideias envolvidas nas operações - com destaque para a equivalência - e isso favoreceu a (re)significação dos conhecimentos profissionais a respeito do seu ensino (BALL, THAMES e PHELPS, 2008). Observamos ainda que, além do estudo, essa ampliação se deu em virtude da colaboração e da relação de confiança estabelecida pelo grupo.

Ainda no tocante à colaboração no âmbito do grupo, na análise do ocorrido nas sessões aqui expostas foi possível identificar algumas das características observadas por Fiorentini (2004); dentre elas, a voluntariedade dos envolvidos; o forte desejo de compartilhamento de saberes e experiências; o sentir-se à vontade para expressar-se livremente e a disposição de ouvir a opinião do outro o que, ao nosso ver, puderam propiciar mudanças de prática. Além disso observamos que houve a reciprocidade de aprendizagem, ou seja, os professores mostraram evidências da ampliação de seus conhecimentos profissionais e os "acadêmicos" ampliaram suas compreensões sobre os saberes experenciais. Acreditamos que tais características potencializaram a (re)significação dos conhecimentos e favoreceram o desenvolvimento dos profissionais envolvidos. 


\section{Referências}

BALL, D. L.; THAMES, M. H.; PHELPS, G. Content Knowledge for Teaching: What Makes it Special? Journal of Teacher Education, 59, 2008. 389-407.

BATURO, A. . \&. N. R. Student teachers' subject matter knowledge within the domain of area measurement. Educational Studies in Mathematics, 3, 1996. 235-268.

BRASIL. SECRETARIA DE ENSINO FUNDAMENTAL. Parâmetros curriculares nacionais. Ministério da Educação e Cultura. [S.l.]. 1997.

CLEMENTS, D. H. . S. M. Measurement in pre-K to grade 2 mathematics. In: D. H. CLEMENTS, J. S. (. ). Engaging young children in Mathematics. Mahwah: Lawrence Erlbaum Associates, 2004. p. 299-317.

FACCO, S. R. Conceito de área: uma proposta de ensino aprendizagem. Pontifícia Universidade Católica de São Paulo. São Paulo, p. 150. 2003.

FIORENTINI, D. Pesquisar práticas colaborativas ou pesquisar colaborativamente? In: BORBA, M. D. C. A. J. L. Pesquisa qualitativa em educação matemática. Belo Horizonte: Autêntica, 2004. p. 47-76.

GARCIA SILVA, Angélica da Fontoura; GALVÃO, Elisa Esteves Lopes; CAMPOS, Tânia Maria Mendonça. Uma interpretação das estratégias utilizadas por um grupo de professores ao calcular área de polígonos em malha quadriculada. Actas del VII CIBEM ISSN, v. 2301, n. 0797, p. 5674, 2013.

GARCIA SILVA, A. F. (2007). O desafio do desenvolvimento profissional docente: Análise da formação continuada de um grupo de professores das séries iniciais do Ensino Fundamental, tendo como objeto de discussão o processo do ensino e aprendizagem de frações. Tese Doutorado em Educação Matemática - PUC São Paulo, São Paulo.

KAMII, C.; KYSH, J. The difficulty of "length×width": Is a square the unit of measurement? Journal of Mathematical Behavior, 25, 2006. 105-115.

NACARATO, A. Educação continuada sob a perspectiva da pesquisa-ação: currículo em ação de um grupo de professoras ao aprender ensinando geometria. Universidade Estadual de Campinas. Campinas, p. 210. 2000.

PESSOA, G. D. S. Um estudo diagnóstico sobre o cálculo de área de figuras planas na malha quadriculada: influência de algumas variáveis. Universidade Federal de Pernambuco. Recife. 2010.

\section{Biografia Resumida}

Angélica da Fontoura Garcia Silva: Professora do Programa de Pós-graduação em Educação Matemática da Universidade ISSN 2526-2882 
Anhanguera de São Paulo e Doutora em Educação Matemática pela PUC-SP.

Link Lattes: Lattes: http://lattes.cnpq.br/5279665144777466

e-mail: angelicafontoura@anhanguera.com

Susana Maris França da Silva: Doutoranda do Programa de Pósgraduação em Educação Matemática da Universidade Anhanguera de São Paulo

Link Lattes: Lattes: http://lattes.cnpq.br/5095997775108716

e-mail: Susana_ditty@hotmail.com

Maria Elisa Esteves Lopes Galvão: Professora do Programa de Pós-graduação em Educação Matemática da Universidade Anhanguera de São Paulo e Doutora em Matemática pela USP.

Link Lattes: Lattes: ttp://lattes.cnpq.br/0294609067982327

e-mail: elisa.galvao@anhanguera.com 